\title{
Resistin, a Novel Host Defense Peptide of Innate Immunity
}

\author{
Yanran $\mathrm{Li}^{1 \dagger}$, Qiyuan Yang ${ }^{1 \dagger}$, Dongjie Cai ${ }^{1 \dagger}$, Hongrui Guo ${ }^{1}$, Jing Fang ${ }^{1}$, Hengmin Cui ${ }^{1}$, \\ Liping Gou ${ }^{1}$, Junliang Deng ${ }^{1}$, Zhisheng Wang ${ }^{2}$ and Zhicai Zuo ${ }^{1 * t}$ \\ ${ }^{1}$ Key Laboratory of Animal Disease and Human Health of Sichuan Province, College of Veterinary Medicine, Sichuan \\ Agricultural University, Chengdu, China, ${ }^{2}$ Institute of Animal Nutrition, Sichuan Agricultural University, Chengdu, China
}

Resistin, a cysteine-rich protein, expressed in adipocytes, was initially proposed as a link between obesity and diabetes in mice. In humans, resistin is considered to be a proinflammatory molecule expressed in immune cells, which plays a regulatory role in many chronic inflammatory diseases, metabolic diseases, infectious diseases, and cancers. However, increasing evidence shows that resistin functions as a host defense peptide of innate immunity, in terms of its wide-spectrum anti-microbial activity, modulation of immunity, and limitation of microbial product-induced inflammation. To date, the understanding of resistin participating in host defense mechanism is still limited. The review aims to summarize current knowledge about the biological properties, functions, and related mechanisms of resistin in host defense, which provides new insights into the pleiotropic biological function of resistin and yields promising strategies for developing new antimicrobial therapeutic agents.

Keywords: resistin, host defense peptide, anti-bacteria, anti-inflammation, immunomodulation, innate immunity

\section{INTRODUCTION}

Host defense peptides are endogenous short-peptide compounds that are recognized as a critical component of the innate immune system and are found in epithelial barriers and circulating leukocytes $(1,2)$. These peptides vary from 10 to 150 amino acids with a net charge between -3 and +20 , which have a broad-spectrum antimicrobial activity and diverse immunomodulatory activities (3-6). Resistin (also called ADSF: adipocyte secreted factor; FIZZ3: found in inflammatory zone) is an $11 \mathrm{kDa}$ or $12.5 \mathrm{kDa}$ cysteine-rich secretory protein that consists of 94 and 108 amino acids in mice and humans, respectively. It is a founding member of the resistin-like molecule (RELM) hormone family, which also includes RELM $\alpha$, RELM $\beta$, and RELM $\gamma$ (7). The structure of resistin mainly comprises a carboxy-terminal disulfide-rich $\beta$-sandwich "head" domain with positive electrostatic surfaces and an amino-terminal $\alpha$-helical "tail" segment with negative electrostatic potential. Resistin was originally proposed as a novel adipocytokine that is involved in insulin resistance and type 2 diabetes in mice (8-11). In contrast to its production by adipocytes in mice, human resistin is expressed predominantly in leukocytes (12-14), and has always been considered as a pro-inflammatory molecule that plays a regulatory role in many human chronic inflammatory diseases (15), metabolic diseases (16), infectious diseases (17-19), and cancers (20). However, recent studies have shown that resistin can directly kill bacteria by damaging their membranes, revealing that resistin may play a role in antimicrobial innate immunity $(21,22)$. Also, resistin can limit inflammation caused by microbial products, and modulate numerous host cellular 
responses (e.g., recruit and activate immune cells, promote the release of proinflammatory cytokines, reinforce interferon (IFN) expression, and promote neutrophil extracellular trap nets (NETs) formation) (23-25). All of these functions favor direct or indirect resolution of infection and reverse potentially harmful inflammation. Therefore, it is becoming significant and necessary to understand the multiple functions and molecular mechanisms of resistin in host defense. The purpose of this review is to provide an overview of the current understanding of resistin as a host defense peptide, with special emphasis on the structure, expression pattern and regulation of resistin, as well as its role and mechanism in host defense. It will provide a new insight into the pleiotropic biological function of resistin and yield promising strategies for developing new antimicrobial therapeutic agents.

\section{STRUCTURE OF RESISTIN}

Resistin belongs to the RELM family, which is characterized by a highly conserved, cysteine-rich $\mathrm{C}$ terminus and shares structural and sequence homology but exhibits significant diversity in expression within their mammalian host (7). RELM $\alpha$ (FIZZ1) is present mainly in adipose tissue and is highly expressed by airway epithelial cells and type 2 pneumocytes during murine allergic pulmonary inflammation $(26,27)$. RELM $\beta$ (FIZZ2) is specifically expressed by goblet cells and epithelial cells mainly in gastrointestinal tract, however, expression by lung epithelial cells in asthmatic patients and mouse models of lung fibrosis is also observed $(27,28)$. RELM $\gamma$ is most highly expressed in the murine hematopoietic system, with high expression in the bone marrow, and lower expression in white blood cells, spleen and thymus (29).

Resistin is a cysteine-rich polypeptide hormone protein that the mouse and human resistin share $46.7 \%$ similarity at the genomic DNA level, 64.4\% sequence homology at the mRNA level, and 59\% identity at the amino acid level (30). The mouse resistin gene is located on chromosome $8 \mathrm{~A} 1$ and encodes an 11 $\mathrm{kDa}$ cysteine-rich polypeptide that consists of 94 amino acids (11). The human resistin gene located on chromosome 19p13.3 encodes a $12.5 \mathrm{kDa}$ cysteine-rich protein that consists of 108 amino acids (30). These polypeptides both have three main domains: an amino $(\mathrm{N})$ terminal signal sequence, a variable middle section, and a conserved carboxyl (C) terminal that determines the signature of the molecule (30-32). Additionally, the protomer comprises a carboxy-terminal disulfide-rich $\beta$ sandwich "head" domain and an amino-terminal $\alpha$-helical "tail" segment (Figure 1A) $(33,34)$. This carboxy-terminal "head" domain adopts a six-stranded jelly-roll topology and contains two three-stranded all-antiparallel sheets $(33,34)$. Three protomers associate through the formation of a parallel coiled-coil. Two trimers are further interlinked to form tail-tail hexamers, linking each protomer from one trimer to a protomer from the associated trimer, and forming a short antiparallel sixhelix bundle $(33,34)$.

At present, the basic functions of different domains of resistin have not been clearly recognized. For instance, the C-terminal globular head domain of resistin is proposed to constitute its protein interaction domain (i.e., the binding of resistin to Tolllike receptor 4 (TLR4) and adenylyl cyclase-associated protein 1 CAP1 $(35,36)$. However, Jang et al. (24) suggest human resistin binds TLR4 mainly through its N-terminal helix. Further studies are needed to confirm it. Besides, the resistin complex exhibits positive electrostatic surfaces in its C-terminal "head" region and negative electrostatic potential in its $\mathrm{N}$-terminal coiled-coil domain (Figure 1B) (33). The "head" region of human resistin also contains several residues exposed to the molecular surface, namely Leu42, Pro46, Phe49, and Trp80, which have been proved to play a role in imparting surface hydrophobicity to the molecule (Figure 1B) (34). Typically, the cationicity and hydrophobicity of the peptides are considered to be two critical elements for their antibacterial action as they are instrumental
A

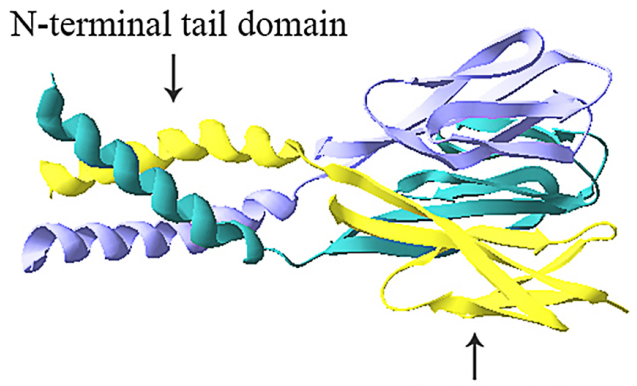

B

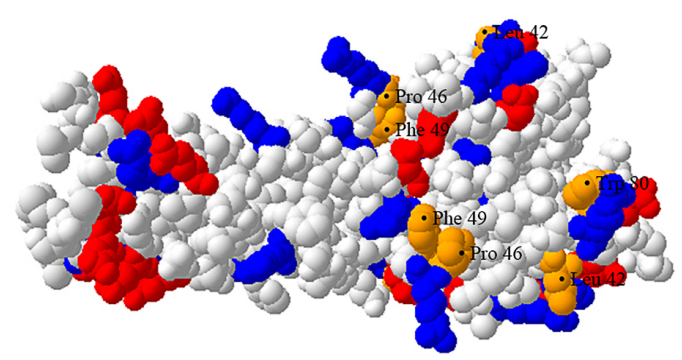

C-terminal head domain

FIGURE 1 | Trimeric structure of human resistin. (A) Ribbon model of resistin trimer showing a C-terminal globular domain containing antiparallel $\beta$-sheets and an $\mathrm{N}$-terminal $\alpha$-helical domain. The three chains are indicated in cyan, yellow and lavender respectively. (B) Space-filled model of human resistin trimer. The basic (positively charged) amino acids, acidic (negatively charged) amino acids, and amino acid residues (Leu42, Pro46, Phe49, and Trp80) constituting the hydrophobic surface of the "head" region are shown in blue, red, and orange respectively. The structure was predicted based on the structure of mouse resistin structure (Protein Data Bank ID code 1RFX) and constructed by using the SWISS-MODEL program (https://swissmodel.expasy.org). 
for binding and insertion into bacterial membranes $(2,37)$. It is, therefore, speculated that the C-terminal "head" domain of resistin may be the molecular basis of its antibacterial activity. Consistent with this, Propheter et al. (21) indicated that mRELM $\beta$ drives membrane permeabilization mainly through its C-terminal $\beta$-sheet structure, which shares $60 \%$ sequence homology with the $\mathrm{C}$ terminus of human resistin at amino acids level. Future studies should further explore how multiple functions of resistin are related to peptide sequences and structures.

Moreover, the analysis of serum samples shows that resistin circulates in different assembly states in mice and humans, and its state determines its biological activity. In mice, resistin was shown to circulate in two distinct assembly states, the predominant high-molecular-mass (HMW) hexamer and the substantially low-molecular-mass (LMW) trimer complex that is unable to form intertrimer disulfide bonds (33). The LMW monomeric form in mice is considered to be more bioactive and potent in terms of hepatic insulin action impairment (33). In humans, resistin circulates as an oligomer with a molecular mass $>660 \mathrm{kDa}$ and a trimer of $45 \mathrm{kDa}$ (38). In contrast to mice, the oligomeric form of human resistin shows a more potent effect on the stimulation of proinflammatory cytokines $(39,40)$. As the concentration of the protein was increased, human resistin tends to form oligomers by the formation of inter/intramolecular disulfide linkages, and that it undergoes a concentrationdependent conformational change in secondary structure from $\alpha$-helical to $\beta$-sheet form (41). This switch can be simply attributed to the hydrophobic effect involving shielding the hydrophobic face from the bulk medium (39). Additionally, studies have shown that the structural conformation of resistin may be involved in maintaining the very fine balance of various physiological and pathological conditions (39).

\section{RESISTIN EXPRESSION PATTERN AND REGULATION}

The resistin has been found to express in various organs/tissues, including adrenal gland, pituitary gland, hypothalamus, white adipose tissue, lung, spleen, intestinal epithelium, placenta, pancreas, stomach, skeletal muscle, skin, and plasma $(22,42)$. Notably, its cell sources and tissue distribution are different among different species. For example, the mouse resistin is almost exclusively expressed in adipocytes of white adipose tissue and is produced during adipocyte differentiation (42). While the human resistin is expressed at very low levels, if at all, in adipocytes, whereas high levels are expressed in leukocytes, including monocytes, macrophages, and neutrophils $(13,43)$. Moreover, recent studies showed that the human resistin is also expressed in keratinocytes and sebaceous glands within the skin epidermis $(22,44)$.

Resistin synthesis and release are differentially regulated, depending on the cell type and the microenvironmental stimuli. In human monocytes/macrophages, resistin expression is up-regulated during monocytes differentiation to macrophages
$(12,45)$, indicating a role for resistin in monocyte/macrophage function. It has been demonstrated that proinflammatory mediators such as LPS, tumor necrosis factor-alpha (TNF- $\alpha$ ), interleukin $1 \beta$ (IL-1 $\beta$ ), and IL-6 can strongly induce the expression of resistin in monocytes/macrophages (12, 46-48). For instance, Actinobacillus pleuropneumoniae-LPS induces porcine alveolar macrophages to produce resistin via MyD88, TRAM, and NF- $\kappa B$ by interacting with TLR4 (49). Besides, the mRNA expression of resistin is also significantly upregulated in human peripheral blood-derived monocytes following exposure to microfilariae or antigen of Brugia malayi $(50,51)$. Unlike in monocytes, resistin is stored in two pools after translation inside neutrophils, the one on the membrane of neutrophils, the other in azurophilic granules and specific granules (14). The membrane-attached resistin is up-regulated following stimulation of neutrophils with small formyl peptide derivates (fMLF) and TNF- $\alpha$. While resistin stored in neutrophils granules is rapidly released when neutrophils are degranulated under the stimulation of fMLF but not TNF $\alpha$ (14). Moreover, some bacteria or selected bacterial components can also induce neutrophils to release resistin (52-57). For instance, Aggregatibacter actinomycetemcomitans-expressed leukotoxin can induce the extracellular release of resistin by interacting with LFA-1 on surface of neutrophils and activating Src family tyrosine kinases (57). High levels of Porphyromonas gingivalisLPS trigger resistin release from human neutrophils through PI3K, JNK, and p38 MAPK (54). Additionally, the surface attachment protein of Streptococcus (e.g., M- or M likeprotein) can also trigger resistin release from neutrophils. This occurs when soluble M1 protein forms complexes with fibrinogen, which are potent activators of neutrophils through interaction with $\beta_{2}$-integrins $(52,56)$. Besides, resistin is also expressed at a low level in human $\mathrm{T}$ and $\mathrm{B}$ cells but significantly increased in B cells when induced by TNF- $\alpha$ (13).

By contrast, the expression of resistin in sebocytes is not only induced by microorganisms and pro-inflammatory cytokines, but also regulated by vitamin $\mathrm{A}$ and its derivatives $(22,44)$. Vitamin A is a lipid-soluble nutrient that is essential for immunity to infection at many body sites $(58,59)$. Vitamin A usually regulates gene transcription through its derivative retinoic acid, which binds to retinoic acid receptors (RARs) $(60,61)$. Harris et al. (22) reported that expression of the human RETN gene in sebocytes is enhanced by the vitamin A derivative retinol through direct binding of RARs to the RETN promoter, revealing that the expression of resistin in human skin may be related to vitamin-A-dependent innate immunity. Notably, the expression of resistin is significantly up-regulated only when the IL-1 $\beta$ and retinol stimulate human sebocytes, whereas it is not or only slightly up-regulated when retinol or IL-1 $\beta$ was used alone to stimulate human sebocytes (22). This indicates that retinol acts synergistically with a proinflammatory stimulus to stimulate human resistin expression in sebocytes. However, Felipe et al. (62) reported that in mice adipocytes, retinoids could inhibit the expression of resistin, suggesting that the regulation of resistin by vitamin-A may be cell typedependent or specie-dependent. 


\section{DIRECT MICROBICIDAL FUNCTION OF RESISTIN}

Surface tissues of the body (e.g., skin, intestinal tract, and lung) are interfaces with the outside environment and are thus continuously exposed to a diverse collection of microorganisms (63). To cope with the substantial microbial exposure, a diverse arsenal of AMPs, such as defensins, cathelicidins, and C-type lectins, are produced by epithelial surfaces to directly kill or inhibit the growth of microorganisms (64-66). Recent studies indicated that resistin is a bactericidal protein expressed in keratinocytes and sebaceous glands of human skin (22). Moreover, the other RELM family members (i.e., mouse and human RELM $\beta$ and mouse RELM $\alpha$ ), have also been identified as antimicrobial proteins expressed in intestinal epithelial cells and skin keratinocytes, respectively, which shape resident body surfaces bacterial communities and limit pathogenic bacterial infection of the body surfaces $(21,22)$. Thus, it is speculated that the RELM family may constitute a previously unknown group of epithelial AMPs that participate in the innate immunity of skin and intestinal mucosa. Here, we make a detailed illustration of the antibacterial functions and action mechanism of resistin or other RELMs in vitro and in vivo.

\section{Antimicrobial Activity In Vitro}

In vitro, human resistin displays a broad-spectrum activity against a variety of Gram-positive and Gram-negative bacteria. For instance, recombinant human resistin was shown to cause a dose-dependent reduction in the viability of strains of the Grampositive species Streptococcus pyogenes and Propionibacterium acnes and the Gram-negative species Pseudomonas aeruginosa, Citrobacter rodentium, Listeria monocytogenes, and Escherichia coli $\mathrm{K} 12(21,22)$. It is effective microbicides even at concentrations in the range of $2.5-10 \mu \mathrm{M}$, and this bactericidal activity functions mainly in the logarithmic phase rather than in the stationary phase of the bacteria $(21,22)$. Strikingly, this bactericidal activity requires low salt concentrations and an acidic $\mathrm{pH}(21,22)$. This is consistent with the salt and $\mathrm{pH}$ sensitivity of other AMPs present on the body surface (67) and may reflect the fact that these bactericidal proteins have evolved to function under the physiological environment of the body. The requirement for these specialized conditions might also explain why resistin was previously reported to lack antibacterial activity (68).

\section{Antibacterial Function In Vivo}

Mutant mouse studies have provided effective evidence for the antibacterial function of epithelial RELM family in vivo and how they protect against pathogens at the skin and gut mucosae. Due to the lack of human resistin in mice, only mutant mouse models with RELM $\alpha$ gene deletion $\left(\right.$ Retnla $\left.^{-/-}\right)$or RELM $\beta$ gene deletion $\left(\right.$ Retnlb $\left.^{-/-}\right)$have been constructed. Retnla ${ }^{-/-}$mice either intradermally or superficially infected with $S$. pyogenes showed elevated numbers of $S$. pyogenes when compared to wild-type mice (22). Consistent with this, clearance of $C$. rodentium in the colons of orally infected mice is considerably diminished in
Retnlb $^{-/-}$mice compared with wild-type mice (21). In each of these mutant models, there was a correlation between the antibacterial activity of the RELMs in vitro and their ability to confer immunity in vivo. Besides, there was a significant two-log increase in the numbers of colonic tissue-associated bacteria in Retnlb $^{-1-}$ compared with wild-type mice. However, these differences did not extend to the colonic luminal bacterial communities, which were at similar amounts between Retnlb $^{-/-}$ mice and wild-type mice (21). This suggests that RELM $\beta$ can limit the association of bacteria with colonic tissues. Moreover, both Retnlb $^{-/-}$mice and Retnla ${ }^{-/}$mice exhibited an altered resident microbiota on the surface of colon tissue or skin (21, 22). Therefore, these investigations show that the RELMs as antibacterial peptides on the skin or intestinal surface not only protect against pathogen colonization but also limit access of the microbiota to host tissues and determine microbiota composition (Figure 2).

In addition to skin, the lung is another important source of resistin (12). In the porcine model of pulmonary infection with Actinobacillus pleuropneumoniae, the expression of resistin was significantly up-regulated in the porcine lung and hilar lymph nodes, indicating that resistin may play a role in the antiinfection immune response of lung $(69,70)$. At present, studies only show that resistin(in humans and pigs but not in mice) have the ability to modulate lung cellular responses, including promoting immune cells recruitment, proinflammatory cytokines expression, and the NETs formation, which may indirectly resist pathogen invasion $(17,23,71)$. However, whether resistin can play a direct bactericidal role as a bactericidal protein in the lung is still unclear, and further research is needed to confirm.

\section{Mechanisms of Antibacterial Activity}

How do AMPs exert their antimicrobial activity? Many hypotheses have been put forward, including: (1) fatal depolarization of the normally energized bacterial membrane (72); (2) the formation of physical holes that cause cellular contents to leak out (73); (3) the activation of fatal processes such as induction of hydrolases that degrade the cell wall (74); (4) the scrambling of the usual distribution of lipids between the leaflets of the bilayer, resulting in disturbance of membrane functions (75); (5) and the damaging of critical intracellular targets after internalization of the peptide (76). Through transmission electron microscope observation and liposome disruption assays, Propheter and Harris et al. $(21,22)$ revealed that resistin and the other RELMs are membrane-permeabilizing proteins that cause bacterial cytoplasmic leakage. The mechanism is that the RELM proteins bind to bacterial lipids and form multimeric pores in membranes through their C-terminal, thus lysing the targeted bacterial cells (Figure 2). In view of this, a question immediately arises as to how these RELM proteins and other cationic AMPs can function in vivo but are not toxic to host cells. One explanation is that unlike bacterial cell membranes, there is a high proportion of cholesterol in mammalian cell membranes. The presence of cholesterol in the target membrane in general reduces the 


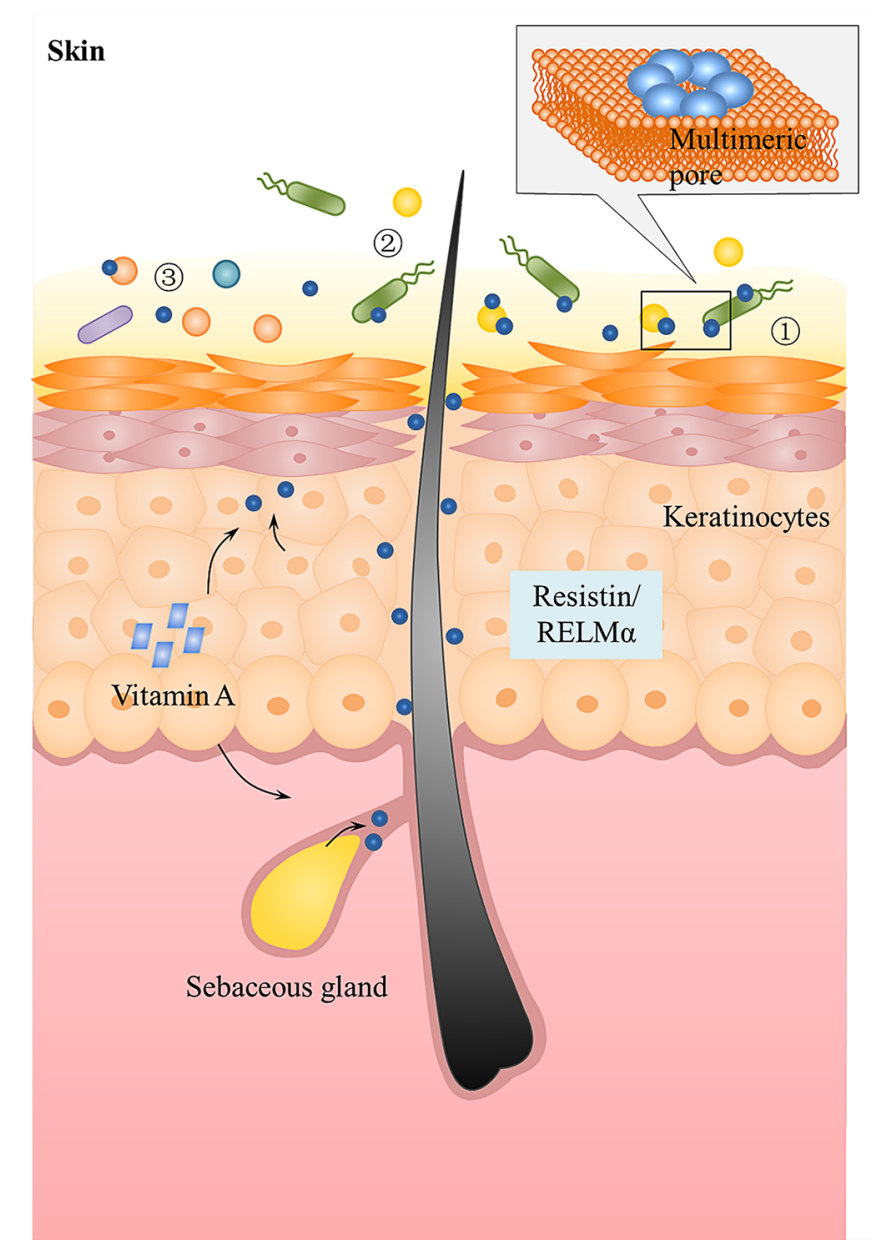

Intestinal tract

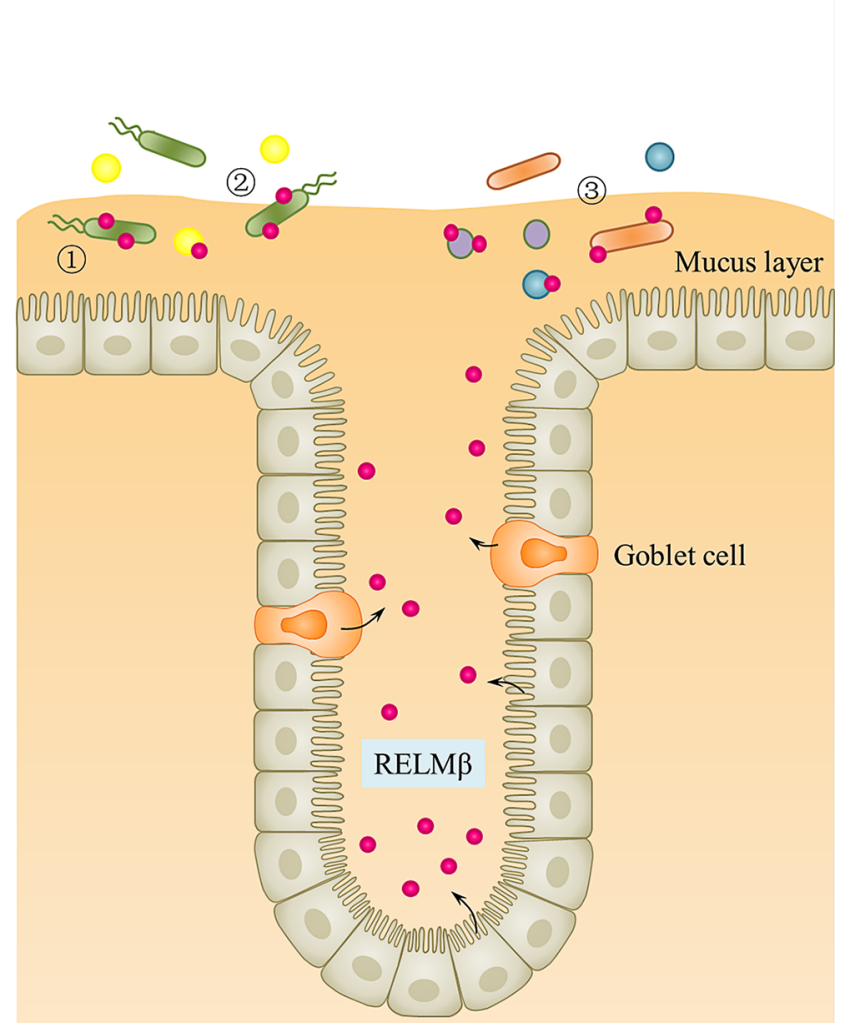

Epithelial cells

FIGURE 2 | Function of resistin and the other RELMs in skin and intestinal epithelium. Human resistin and mouse RELM $\alpha$ are expressed in keratinocytes and sebaceous glands of skin that can be triggered by bacterial colonization and Vitamin A. Mouse and human RELM $\beta$ are expressed by goblet cells and epithelial cells into gastrointestinal tract mucus layer. They kill bacteria by binding to bacterial lipids and forming multimeric pores in bacterial membranes. All RELMs not only (1) protect against pathogen colonization, but also (2) limit access of the microbiota to host tissues and (3) determine microbiota composition.

activity of AMPs, due either to stabilization of the lipid bilayer or to interactions between cholesterol and the peptide $(4,77)$. Consistent with this, the RELM $\alpha$ was shown to be significantly less disruptive to liposomes containing 30\% cholesterol than cholesterol-free liposomes (22). Besides cholesterol, the significant differences in lipid compositional and membrane potential between the prokaryotic and eukaryotic membranes also contribute to cell selectivity of cationic AMPs. The outer surface of Gram negative bacteria is covered in lipopolysaccharides and Gram positive bacteria present a surface of teichoic acids, resulting in both classes of bacteria having negatively charged cell surfaces (78). In contrast, most mammalian cell membranes have an outer leaflet comprised of zwitterionic phosphotidylcholine and sphingomyelin phospholipids, whilst the inner leaflet is composed of phosphatidylserine leading to an essentially neutral surface (79). Therefore, the positively charged AMPs may primarily bind to and permeabilize the negatively charged bacterial membrane rather than that of mammalian cells $(75,80)$. Consistent with this, Propheter et al. (21) found that RELM $\beta$ binds to lipids bearing negatively charged lipid head groups (phosphatidylserine and phosphatidic acid), but not to zwitterionic or neutral lipids. And in liposome disruption assays, RELM $\beta$ induced rapid dye efflux from liposomes composed of both phosphotidylcholine and phosphatidylserine, while the rate of efflux was reduced when phosphotidylcholineonly liposomes were used (21), which further proves this view. Liposomes composed of phosphatidylserine alone also yielded a reduced rate of dye efflux, suggesting that charge density is an important factor for the RELMs membrane-disrupting activity, a characteristic shared with other cationic AMPs.

Currently, several different models (i.e., the barrel-stave, carpet, detergent, toroidal pore, and aggregate models) have been proposed to explain how, following initial attachment, antibacterial peptides insert into the bacterial membrane to form transmembrane pores which result in membrane 
permeabilization $(75,80)$. Nonetheless, the mechanisms utilized by the RELM family have not been as well studied.

\section{RESISTIN MOLECULAR FUNCTIONS ON ITS RECEPTORS}

Up till now, there have been many reports about resistin receptors (e.g., TLR4 (36), CAP1 (35), G-protein-coupled receptors (GPCRs) (81), an isoform of decorin $(\triangle \mathrm{DCN})(82)$, and receptor tyrosine kinase-like orphan receptor 1 (ROR1) (83), but no study can powerfully prove the existence of specific receptor for resistin. Resistin exhibits differential binding affinity towards these receptors in different tissues and cell types, thus leading to the activation of diverse cell signaling pathways. Among them, TLR4 and CAP1 serve as the most studied in vivo functional receptors for resistin.

\section{TLR4}

TLR4 is a cell surface receptor that plays an important role in resistin-induced inflammation. For instance, Tarkowski et al. (36) first demonstrated that resistin can promote the production of IL-1 $\beta$, IL- 6 , and TNF- $\alpha$ in human leucocytes, monocytic cell line THP1, and epithelial cells (HEK293) for binding to TLR4 and activating its downstream NF- $\mathrm{BB}$ and MAP-kinases signaling pathway. In porcine alveolar macrophages, resistin promoted the production of pro-inflammatory cytokines via TLR4/NF-אB-mediated pathway (TLR4, MyD88/TRAM, and NF- $\mathrm{KB}$ ) (71). In SH-SY5Y human neuroblastoma cells, resistin inhibited autophagy and increased inflammation by binding to TLR4, inhibiting AMPK phosphorylation, and activating the Akt-mTOR signaling pathways (84). In human nucleus pulposus cells, resistin promoted CCL4 expression through Toll-like receptor-4 and activation of the p38-MAPK and NF$\kappa \mathrm{B}$ signaling pathways, and this expression causes infiltration of macrophage (85). Besides, LPS is known as the main ligand for TLR4. However, when co-stimulation of human peripheral blood mononuclear cells (PBMCs) with resistin and LPS, resistin significantly diminished the LPS-induced production of proinflammatory cytokines $(24,36)$, suggesting that resistin is an endogenous inhibitor of LPS interaction with TLR4 rather than a co-factor of such an interaction. Consistent with this, in a Nippostrongylus brasiliensis $(\mathrm{Nb})$-infected human resistin gene expressing transgenic $\left(\mathrm{hRETNTg}^{+}\right)$mice model in which a lethal dose of LPS was injected simultaneously, resistin decreased circulating proinflammatory and Th1 cytokines (e.g., TNF $\alpha$, interferon-gamma (IFN- $\gamma$ ), IL-6, IL-12, IL- $1 \alpha$, and granulocyte-macrophage colony-stimulating factor (GM-CSF)), and increased anti-inflammatory cytokine IL-10 through TLR4 (24). However, in the model of $\mathrm{Nb}$-infected $\mathrm{hRETNTg}^{+}$mice, resistin significantly increased TLR4 signaling, chemokines, and pro-inflammatory cytokines (17). The accepted explanation to date is that resistin competes with LPS/MD2 for binding to TLR4 and suppresses pro-inflammatory signaling (i. e., NF- $\kappa \mathrm{B}$ ) while promotes anti-inflammatory signaling (i.e., STAT3, TBK1) (24, 36). However, according to the fact that most AMPs can directly bind to LPS and neutralize its inflammatory (endotoxin) activity $(77,86-88)$, we speculate that this anti-inflammatory property of resistin may also be the result of neutralizing LPS (Figure 3). For example, bactericidal/permeability-increasing protein (BPI) binds the lipid A region of LPS with high affinity, thereby preventing its interaction with other LPS-binding molecules, including LBP and CD14 (89). In this scenario, resistin acts as a scavenger for the activating ligand, removing it before it can trigger inflammation through TLR4. Further studies are needed to confirm it.

\section{CAP1 and Others}

CAP1 is an actin-binding protein, which have three main domains: a carboxy-terminal domain that binds to actin, a central proline-rich domain, and an amino-terminal domain of the unknown function (90). Studies have shown that resistin can directly bind to CAP1 and up-regulate cyclic adenosine monophosphate (cAMP) concentrations, protein kinase $\mathrm{A}$ (PKA) activity, and the NF- $\kappa \mathrm{B}$-related transcription of inflammatory cytokines in THP-1 cells (35). However, CAP1 is an intracellular receptor with no predicted transmembrane domain. Therefore, it is likely that resistin may need to bind a surface receptor, such as TLR4, for endocytosis and presentation to CAP1 (Figure 3) $(35,91)$. As for GPCRs, studies have shown that the migration of human CD4 positive lymphocytes induced by resistin may involve the activation of pertussis toxin-sensitive G-protein-coupled receptors, but the interaction between them cannot be effectively proved (81). Decorin and ROR1 are receptors for murine resistin and do not seem to mediate inflammatory responses in humans. Daquinag et al. (83) identified $\triangle \mathrm{DCN}$ as a functional resistin receptor that may regulate WAT expansion in adipocyte progenitors by modulating cell migration and proliferation and adipocyte differentiation. Sánchez-Solana et al. (82) showed that the interaction of murine resistin with ROR1 in 3T3-L1 preadipocytes leads to the activation of extracellular signalregulated kinases 1 and $2(\mathrm{ERK} 1 / 2)$. Murine resistin can also modulate adipogenesis and glucose uptake in 3T3-L1 preadipocytes through the ROR1 receptor.

\section{IMMUNOMODULATORY FUNCTION OF RESISTIN}

In addition to controlling bacterial burden by direct antimicrobial action, evidence suggests that resistin can indirectly resist microbial invasion/infection by modulating host cellular function, such as activating immune cells and enhancing the production of pro-inflammatory cytokines, inhibiting inflammation induced by microbial products, promoting the formation of NETs, acting as chemokines and/ or inducing chemokines production, and enhancing the expression of IFN $\lambda$. Besides, the presence of resistin can also contribute to a disturbed immune response in certain contexts and diseases, suggesting that resistin may be a bidirectional immunomodulatory molecule. Here, we review some of the 


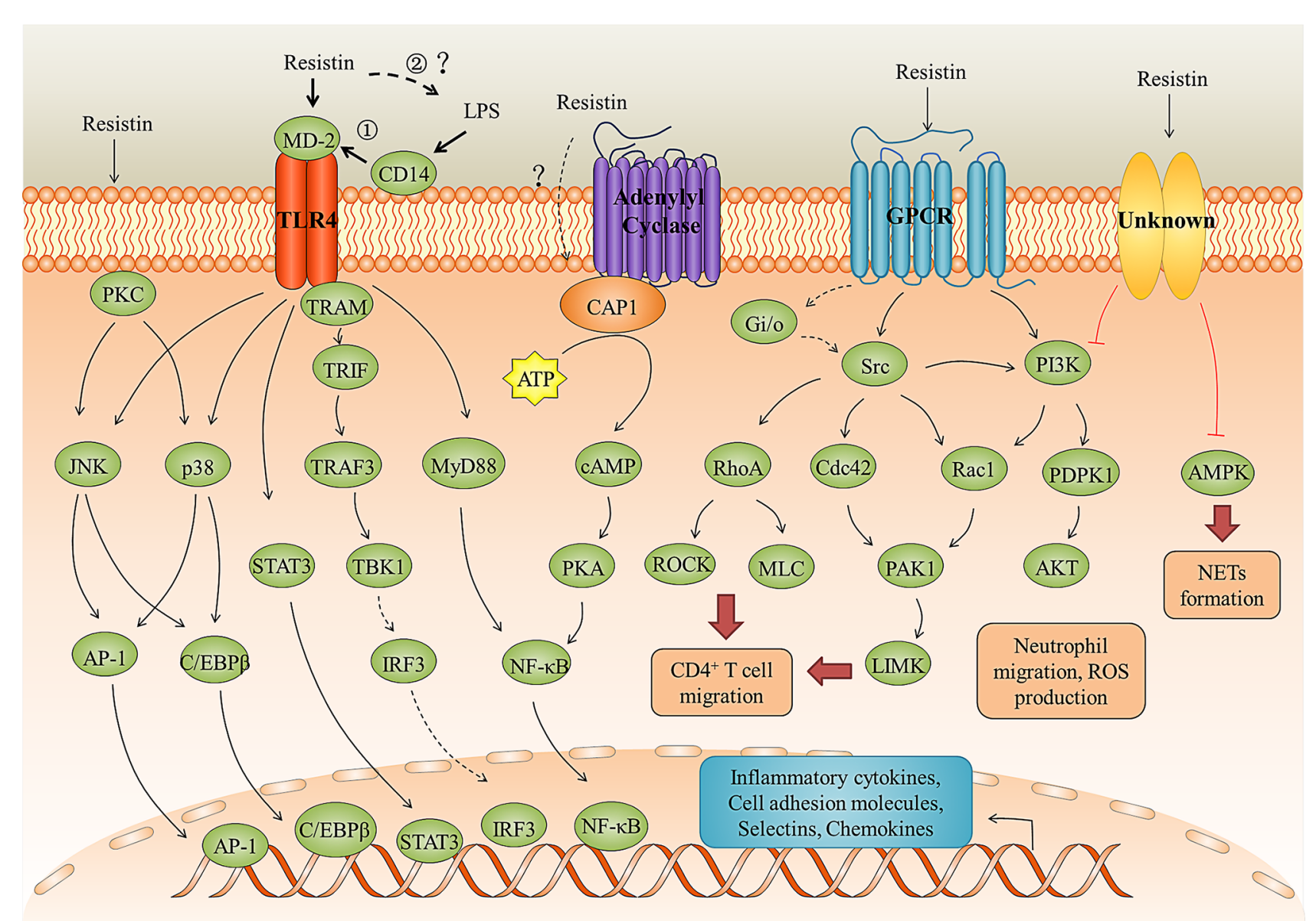

FIGURE 3 | Resistin signaling pathways in inflammation and immune regulation. Resistin binding to the TLR4, CAP1 receptors, GPCR, and unknown receptors activates several signaling pathways leading to the immune cell activation and migration, neutrophil dysfunction, pro-inflammatory cytokines and chemokines production, and NETs formation. The anti-LPS-induced inflammation mediated by resistin through TLR4 may be in two ways: (1) Resistin competes with LPS/MD2 for


LPS and neutralize its inflammatory (endotoxin) activity.

important immunomodulatory functions of resistin that are not related to their direct antimicrobial action.

\section{Inflammatory Regulation Activity}

Studies have shown that resistin can act as a proinflammatory cytokine, activating immune cells and promoting the secretion of proinflammatory cytokines. For instance, resistin activated mouse macrophage-like (RAW264.7) cell, human macrophagelike (U-937) cells, THP-1 cells, porcine alveolar macrophages, and PBMCs, and promoted the production of pro-inflammatory cytokines (i.e., IL-6, IL-1 $\beta$, and TNF- $\alpha$ )via TLR4 or CAP1mediated signaling pathways $(36,40,71)$. It also sensitized neutrophils to LPS stimulation and enhance the production of TNF- $\alpha$ and MIP-2 by inhibiting the activation of AMPK in LPSinduced neutrophils (23). Additionally, Jang et al. (17) reported that resistin upregulated pro-inflammatory gene expression (i.e., IL-6 and TNF- $\alpha$ ) from monocytes and neutrophils in $\mathrm{hRETNTg}^{+}$ mice $\mathrm{Nb}$ infection, which promoted a pro-inflammatory cytokine environment and tipped the balance from type 2 to type 1 cytokines. Strikingly, although this inflammatory environment was negatively impact the host immune response to helminths (e.g., delaying parasite expulsion and exacerbating lung inflammation), the genome-wide transcriptional profiling of $\mathrm{Nb}$-infected lung tissue reveals that resistin can up-regulate almost all the gene ontology-defined immune response genes and defense genes (17). Therefore, it is speculated that the existence of resistin may direct the immune response towards combating more fatal bacterial or viral infections in an environment where viral- or bacterial-helminth co-infections are common.

Consistent with this, Jang et al. (24) identified a protective function for human resistin promoted helminth-induced immunomodulation, with increased survival of Nippostrongylus brasiliensis $(\mathrm{Nb})$-infected $\mathrm{h} R E T N \mathrm{Tg}^{+}$mice after a fatal LPS dose compared with naive mice or $\mathrm{Nb}$-infected $\mathrm{h} R E T N \mathrm{Tg}^{-}$mice. As mentioned before, this protective effect of resistin is related to its 
ability to block LPS proinflammatory function $(24,36)$. Besides, resistin can also reduce the inflammatory response induced by lipoteichoic acid (LTA). LTA is a major cell wall component of Gram-positive bacteria, which is considered to be the counterpart of LPS derived from Gram-negative bacteria (92). Studies have shown that resistin suppressed the production of pro-inflammatory cytokines such as IL-6, TNF-a, and IL-12 p40 in human dendritic cells (DCs) when stimulated by LTA from Staphylococcus aureus (93), but the exact mechanism is still unknown.

Collectively, all these observations indicate that resistin has an important role in regulating and balancing inflammatory responses to microbes. Resistin itself or in the case of helminths infection can enhance the host inflammatory response, that further refine and amplify the innate immune response. However, in the case of bacterial-helminth coinfections or stimulation of bacterial products (i.e., LPS, LTA), resistin may inhibit the inflammation associated with microbial challenge. Although the central question regarding the mechanisms by which resistin triggers a switch from proinflammatory response to anti-inflammatory response is yet to be clarified, the overall capacity of resistin to regulate inflammation in different environments leads to the conclusion that it is not only involved in suppressing uncontrolled microbial growth, but also modifies inflammation, which prevents microbial products from causing excessive inflammatory damage to the host.

\section{Enhanced Extracellular Bacterial Killing}

Intriguingly, resistin has also been suggested to kill microorganisms through another innate immune mechanism known as neutrophil extracellular trap nets (NETs). NETs are extracellular strands of decondensed DNA in complex with histones and granule proteins, which were expelled from dying neutrophils to ensnare and kill microbes $(94,95)$. Studies have shown that exposure of neutrophils to resistin resulted in enhanced phosphorylation of the NADPH oxidase subunit p40phox and NETs formation, as well as increased extracellular concentrations of the alarmins HMGB1 and histone 3 in association with NETs (23). Similarly, the increased NET formation was found in the lungs of $\mathrm{hRETNTg}{ }^{+}$mice subjected to LPS instillation (23). However, Bonavia et al. (96) reported that resistin didn't affect the extracellular bacterial clearance (i.e., neutrophil phagocytosis or extracellular clearance via NETs) of $P$. aeruginosa by neutrophilic-differentiated NB4 cells. These contradictory findings may reveal the context-dependence of resistin's cellular effects.

\section{Chemotactic Activity}

The migration of immune cells to inflamed and infected tissues is a fundamental process of the innate immune response $(97,98)$. The mechanisms responsible for the selective recruitment of immune cells into tissues (under homeostatic or inflammatory conditions) are thought to involve cytokines that activate the expression of the E-selectin and P-selectin, intercellular cell adhesion molecule-1 (ICAM-1), and vascular cell adhesion molecule-1 (VCAM-1), as well as leukocyte-specific chemoattractant such as chemokines (99). Studies have shown that resistin can indirectly promote the recruitment of effector cells such as neutrophils, monocytes, and macrophages by stimulating selectins, cell adhesion molecules, and chemokines secretion from a variety of cell types (23, 100-102). For instance, resistin up-regulates the expression of chemokines (i.e., CCL2, CCL3, CCL4, CCL5, CXCL1, and CXCL2) via transcription factors NF- $\mathrm{KB}$ and $\mathrm{C} / \mathrm{EBP} \beta$ in human articular chondrocytes (100). It enhances VCAM-1 expression and monocyte adhesion through the PKC, p38, and JNK signaling pathways in human osteoarthritis synovial fibroblasts (103). In endothelial cells, resistin up-regulates ICAM-1, VCAM-1, fractalkine, and MCP1 via TLR4, JNK/p38, AP-1, and NF- $\mathrm{KB}$ dependent pathways or by Gi/o signaling pathway (104-108). Another mechanism by which resistin induces the expression of $\mathrm{P}$-selectin and fractalkine in endothelial cells is the activation of the transcription factor STAT3 and the up-regulation of SOCS3 expression (109).

Notably, resistin itself also possesses direct chemotactic activity (Figure 4). Jang et al. (17) found that in vivo treatment of mice with recombinant resistin led to rapid monocyte recruitment that preceded the increased expression of monocyte chemokine signaling genes, including CCR2, CXCL10, suggesting that monocytes can be directly recruited by resistin, and in turn begin to express chemokines as part of a positive feedback loop to promote immune activation. In line with this, resistin showed a direct chemoattractive effect on THP1 cells and their enhanced migration toward MCP-1 (110). Additionally, resistin also acts directly as a chemoattractant of CD4-positive lymphocytes by binding pertussis toxin-sensitive G-protein-coupled receptors, activating Src-kinase, PI-3 kinase, RhoA, Rac1, Cdc42, PAK, LIMK, ROCK, and phosphorylating MLC (Figure 3) (81).

\section{Enhanced Anti-Viral Immune Response}

Furthermore, resistin can also regulate anti-viral immune responses by affecting the expression of interferon. Interferon is a group of low molecular glycoproteins with similar structures and functions produced by host cells when the body is infected with viruses, and it is the most important immune factor against virus infection (111). Studies have shown that resistin can enhance host immunity against $\mathrm{HCV}$ infection by reinforcing interferon $\lambda$-3(IFNL3) to eliminate hepatitis $C$ virus (25).

\section{Resistin and Immunosuppression}

Studies have shown that patients with type 2 diabetes mellitus, chronic kidney disease, acute kidney injury, Mycobacterium tuberculosis infection, and sepsis show increased resistin levels in plasma but also an increased occurrence of infections $(68,96$, $112-114)$. It is mainly because resistin can cause a dose-dependent impairment in neutrophil migration, ROS production, and intracellular bacterial clearance by inhibiting activation of PI3K, PDPK1, and Akt in neutrophils. Notably, this inhibition was observed only when plasma resistin concentrations were $>20 \mathrm{ng} /$ $\mathrm{ml}$, but not at normal physiological concentrations $(\leq 20 \mathrm{ng} / \mathrm{ml})$ (Figure 4) $(96,114)$, suggesting that resistin's cellular effects are context- or disease-dependent. Up to now, the in vivo mode of 


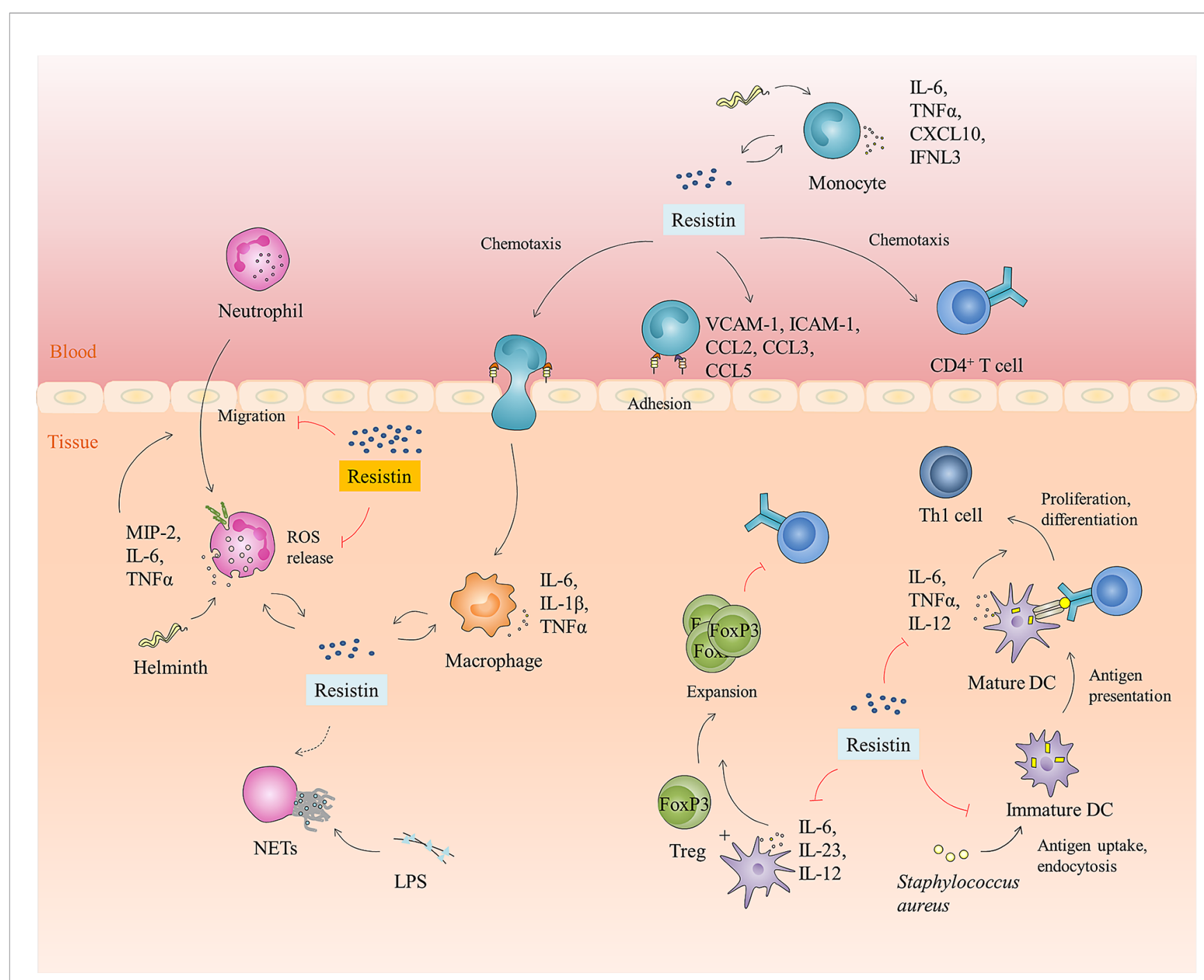

FIGURE 4 | Immunomodulatory function of resistin. Resistin is involved in the host anti-infection immune process by interacting with a variety of immune cell types in humans. It can directly or indirectly promote the adhesion, infiltration, and migration of human monocytes, neutrophils, and CD4 ${ }^{+} \mathrm{T}$ cells. Likewise, resistin can activate monocytes, macrophages, and neutrophils, promote pro-inflammatory cytokines production, and reinforce IFNL3 expression. Moreover, it can also enhance extracellular bacterial killing, namely promote the formation of NETs. However, in certain diseases or contexts, resistin impedes human neutrophils' function by inhibiting neutrophils migration and ROS production. It also inhibits antigen uptake, endocytosis, and cytokine production of human DCs, induces expansion of Tregs, and suppresses the proliferation and differentiation of CD4 ${ }^{+} \mathrm{T}$ cells into Th1 cells by regulating DCs.

action of resistin on this disturbed immune response has not been clarified. Miller et al. (68) indicated that human resistin can directly impair neutrophil killing of Gram-positive and Gramnegative organisms, while it does not affect the ability of monocytes and macrophages to kill bacteria. However, Nieto et al. (115) reported that resistin can directly reduce the inflammatory phenotype of monocytes and TNF- $\alpha$ production and thus indirectly reduce the oxidative burst of neutrophils.

Besides, when co-cultured with Staphylococcus aureusprimed DCs, human resistin can inhibit antigen uptake, endocytosis, and cytokine production (i.e., IL-6, TNF-a, and IL-12 p40) of DCs and thus suppress proliferation and differentiation of $\mathrm{CD}^{+} \mathrm{T}$ cells into Th1 cells (93). It can also indirectly induce the expansion of Tregs by inhibiting the expression of IRF-1 and its target cytokines, IL-6, IL-23p19 and IL- $12 \mathrm{p} 40$ in DCs when $\mathrm{CD} 4^{+} \mathrm{T}$ cells are co-cultured with DCs (Figure 4) $(116,117)$.

\section{PERSPECTIVES}

In conclusion, as a newly identified host defense peptide (HDP), resistin has the following biological properties (Figure 5): (i) it is a $12.5 \mathrm{kDa}$ small molecule protein that consists of 108 amino acids; (ii) it has a positively charged and surface hydrophobic carboxy-terminal $\beta$-sandwich "head" domain; (iii) it is mainly expressed in leukocytes and skin epithelial cells in humans; and (iv) it has direct antibacterial, inflammation regulatory, 


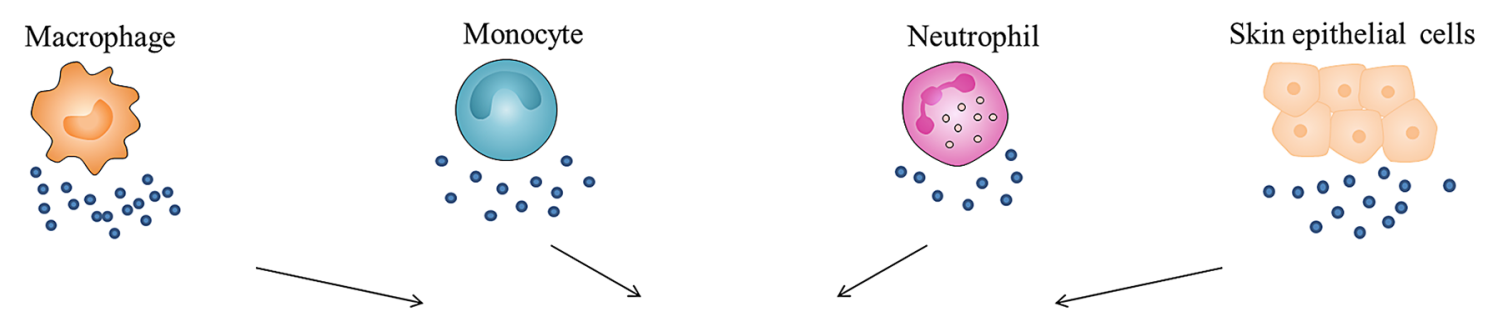

Resistin

(108aa; $12.5 \mathrm{kDa})$

Host defense peptide



Directly kills bacteria

- Disrupt bacterial membranes
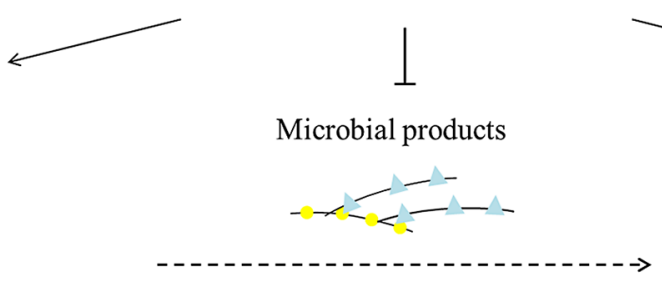

Limits inflammation

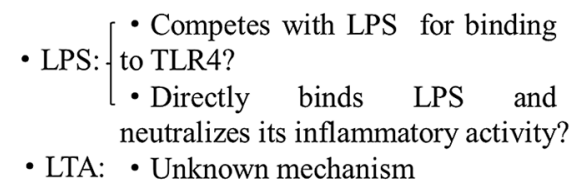

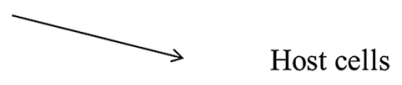

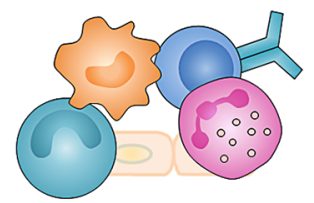

Modulates host immunity

- Recruits and activates immune cells - Promotes pro-inflammatory cytokines production

- Promotes NETs formation

- Enhances IFNL3 expression

- Inhibits the basic function of neutrophils and DCs

FIGURE 5 | Role of resistin in host defense. Leukocytes (i.e., macrophage, monocyte, and neutrophil) and skin epithelial cells-derived resistin act as host defense peptide, and participate in the innate anti-infection immunity of the host at least three ways: they directly kill bacteria; they regulate and balance the inflammatory response to microbial products (LPS and LTA); and they activate and amplify the host immune response to indirectly resist microbial infection.

and immunomodulatory functions. Upon exposure to danger, it is becoming clear that resistin is essential not only for inhibiting microbial growth, but also for attenuating exacerbated inflammatory responses and stimulating certain beneficial aspects of inflammation and immunity, which is important for creating an overall balance. Although the current studies have provided effective evidence for the multifaceted biological functions of resistin in host defense, we also find that there are still missing or conflicting information to be solved urgently. For example, many distinct resistin-binding functional receptors have been identified so far, but the specific receptor of resistin and its corresponding signaling pathways need to be further studied. Additionally, when discussing the inflammatory regulation function and related mechanism of resistin, we found that resistin itself, as a pro-inflammatory cytokine, can activate immune cells and promote the secretion of proinflammatory cytokines. However, resistin shows antiinflammatory activity under the condition of bacterial infection or stimulation by bacterial products (LPS). The accepted explanation to date is that resistin competes with LPS/MD2 for binding to TLR4 and suppresses pro-inflammatory signaling (i.e., NF- $\mathrm{\kappa B}$ ) while promotes anti-inflammatory signaling (i.e., STAT3, TBK1). However, according to the fact that most HDPs have a high affinity for lipopolysaccharide, we propose a hypothesis, that is, whether this anti-inflammatory property is the result of the direct combination of resistin and LPS, thus eliminating LPS before its interaction with TLR4, which is worth further study.

With the growing problem of resistance to and overuse of conventional antibiotics, it is particularly important to explore new antibacterial drugs or new treatment strategies to combat infectious diseases. There is no doubt that HDPs represent the attractive worthwhile candidates to pursue as therapeutic molecules owing to their small size, widespread occurrence among animals and plants, and potent antimicrobial and immunomodulation functions. Therefore, future work should 
focus on gaining a precise understanding of how resistin acts at the molecular level, that is how the peptide sequence and molecular structure of resistin influence its antibacterial, inflammation and immune regulation functions, which are likely to yield promising strategies for developing new antimicrobial therapeutic agents.

\section{AUTHOR CONTRIBUTIONS}

YL wrote the manuscript. ZZ, YL, QY, and DC conceived the review and designed the figures. HG and JF helped with the literature and polish the manuscript. HC, LG, JD, and ZW gleaned the material and scrutinized the manuscript. All authors contributed to the article and approved the submitted version.

\section{REFERENCES}

1. Prasad SV, Fiedoruk K, Daniluk T, Piktel E, Bucki R. Expression and Function of Host Defense Peptides at Inflammation Sites. Int J Mol Sci (2019) 21(1):104. doi: 10.3390/ijms21010104

2. DeLong MR, Tandon VJ, Da Lio AL, Deming TJ, Cederna PS. Overview of Host Defense Peptides and Their Applications for Plastic and Reconstructive Surgeons. Plast Reconstr Surg (2020) 146(1):91-103. doi: 10.1097/PRS.0000000000006910

3. Lai Y, Gallo RL. Amped Up Immunity: How Antimicrobial Peptides Have Multiple Roles in Immune Defense. Trends Immunol (2009) 30(3):131-41. doi: 10.1016/j.it.2008.12.003

4. Choi KY, Chow LN, Mookherjee N. Cationic Host Defence Peptides: Multifaceted Role in Immune Modulation and Inflammation. J Innate Immun (2012) 4(4):361-70. doi: 10.1159/000336630

5. Mansour SC, Pena OM, Hancock REW. Host Defense Peptides: Front-Line Immunomodulators. Trends Immunol (2014) 35(9):443-50. doi: 10.1016/ j.it.2014.07.004

6. Wang G. Human Antimicrobial Peptides and Proteins. Pharmaceuticals (2014) 7(5):545-94. doi: 10.3390/ph7050545

7. Pine GM, Batugedara HM, Nair MG. Here, There and Everywhere: ResistinLike Molecules in Infection, Inflammation, and Metabolic Disorders. Cytokine (2018) 110:442-51. doi: 10.1016/j.cyto.2018.05.014

8. Steppan CM, Lazar MA. Resistin and Obesity-Associated Insulin Resistance. Trends Endocrinol Metab (2002) 13(1):18-23. doi: 10.1016/s1043-2760(01) 00522-7

9. Li F, He J, Li Z, Luo Z, Yan L, Li Y. Effects of Resistin Expression on Glucose Metabolism and Hepatic Insulin Resistance. Endocrine (2009) 35(2):243-51. doi: 10.1007/s12020-009-9148-4

10. Palanivel R, Maida A, Liu Y, Sweeney G. Regulation of Insulin Signalling, Glucose Uptake and Metabolism in Rat Skeletal Muscle Cells Upon Prolonged Exposure to Resistin. Diabetologia (2006) 49(1):183-90. doi: 10.1007/s00125-005-0060-z

11. Steppan CM, Bailey ST, Bhat S, Brown EJ, Banerjee RR, Wright CM, et al. The Hormone Resistin Links Obesity to Diabetes. Nature (2001) 409 (6818):307-12. doi: 10.1038/35053000

12. Patel L, Buckels AC, Kinghorn IJ, Murdock PR, Holbrook JD, Plumpton C, et al. Resistin is Expressed in Human Macrophages and Directly Regulated by PPAR Gamma Activators. Biochem Biophys Res Commun (2003) 300 (2):472-6. doi: 10.1016/s0006-291x(02)02841-3

13. Kunnari AM, Savolainen E, Ukkola OH, Kesäniemi YA, Jokela MA. The Expression of Human Resistin in Different Leucocyte Lineages Is Modulated by LPS and Tnfo. Regul Pept (2009) 157(1-3):57-63. doi: 10.1016/ j.regpep.2009.05.002

14. Boström EA, Tarkowski A, Bokarewa M. Resistin Is Stored in Neutrophil Granules Being Released Upon Challenge With Inflammatory Stimuli.

\section{FUNDING}

This research was funded by the National Key Research and Development Project (Grant No. 2018YFD0501800), Sichuan Science and Technology Program (Grant No. 2018NZ0002), and the Sichuan Beef Cattle Innovation Team of National Modern Agricultural Industry Technology System (Grant No. SCCXTD-2020-13)

\section{ACKNOWLEDGMENTS}

This work was supported financially by the National Key Research and Development Project, Sichuan Science and Technology Program, and the Sichuan Beef Cattle Innovation Team of National Modern Agricultural Industry Technology System.

Biochim Biophys Acta (2009) 1793(12):1894-900. doi: 10.1016/j.bbamcr. 2009.09.008

15. Shanshan PYL. Role of Resistin in Inflammation and Inflammation-Related Diseases. Cell Mol Immunol (2018) 3(1):29-34. doi: 10.16/j.cellimm.2006.05.006

16. Mostafazadeh M, Haiaty S, Rastqar A, Keshvari M. Correlation Between Resistin Level and Metabolic Syndrome Component: A Review. Horm Metab Res (2018) 50(7):521-36. doi: 10.1055/a-0637-1975

17. Jang JC, Chen G, Wang SH, Barnes MA, Chung JI, Camberis M, et al. Macrophage-Derived Human Resistin Is Induced in Multiple Helminth Infections and Promotes Inflammatory Monocytes and Increased Parasite Burden. PloS Pathog (2015) 11(1):e1004579. doi: 10.1371/journal.ppat.1004579

18. Liu K, Liu Y, Lin C, Tsai M, Hsu Y, Yen M, et al. Serum Neutrophil Gelatinase-Associated Lipocalin and Resistin Are Associated With Dengue Infection in Adults. BMC Infect Dis (2016) 16(1):441. doi: 10.1186/s12879016-1759-9

19. Mantula PS, Outinen TK, Jaatinen P, Hämäläinen M, Huhtala H, Pörsti IH, et al. High Plasma Resistin Associates With Severe Acute Kidney Injury in Puumala Hantavirus Infection. PloS One (2018) 13(12):e0208017. doi: 10.1371/journal.pone.0208017

20. Sudan SK, Deshmukh SK, Poosarla T, Holliday NP, Dyess DL, Singh AP, et al. Resistin: An Inflammatory Cytokine With Multi-Faceted Roles in Cancer. Biochim Biophys Acta Rev Cancer (2020) 1874(2):188419. doi: 10.1016/j.bbcan.2020.188419

21. Propheter DC, Chara AL, Harris TA, Ruhn KA, Hooper LV. Resistin-Like Molecule $\beta$ is a Bactericidal Protein That Promotes Spatial Segregation of the Microbiota and the Colonic Epithelium. Proc Natl Acad Sci USA (2017) 114 (42):11027-33. doi: 10.1073/pnas.1711395114

22. Harris TA, Gattu S, Propheter DC, Kuang Z, Bel S, Ruhn KA, et al. ResistinLike Molecule $\alpha$ Provides Vitamin-A-Dependent Antimicrobial Protection in the Skin. Cell Host Microbe (2019) 25(6):777-88.e8. doi: 10.1016/ j.chom.2019.04.004

23. Jiang S, Park DW, Tadie J, Gregoire M, Deshane J, Pittet JF, et al. Human Resistin Promotes Neutrophil Proinflammatory Activation and Neutrophil Extracellular Trap Formation and Increases Severity of Acute Lung Injury. J Immunol (2014) 192(10):4795-803. doi: 10.4049/jimmunol.1302764

24. Jang JC, Li J, Gambini L, Batugedara HM, Sati S, Lazar MA, et al. Human Resistin Protects Against Endotoxic Shock by Blocking LPS-TLR4 Interaction. Proc Natl Acad Sci USA (2017) 114(48):E10399-408. doi: $10.1073 /$ pnas.1716015114

25. Chang M, Liang K, Ku C, Lo C, Cheng Y, Hsu C, et al. Resistin Reinforces Interferon $\lambda-3$ to Eliminate Hepatitis C Virus With Fine-Tuning From RETN Single-Nucleotide Polymorphisms. Sci Rep (2016) 6:30799. doi: $10.1038 /$ srep30799

26. Holcomb IN. FIZZ1, a Novel Cysteine-Rich Secreted Protein Associated With Pulmonary Inflammation, Defines a New Gene Family. EMBO J (2000) 19(15):4046-55. doi: 10.1093/emboj/19.15.4046 
27. Steppan CM, Brown EJ, Wright CM, Bhat S, Banerjee RR, Dai CY, et al. A Family of Tissue-Specific Resistin-Like Molecules. Proc Natl Acad Sci (2001) 98:502-6. doi: 10.1073/pnas.98.2.502

28. Liu T, Baek HA, Yu H, Lee HJ, Park B, Ullenbruch M, et al. Fizz2/Relm- $\beta$ Induction and Role in Pulmonary Fibrosis. J Immunol (2011) 187:450-61. doi: 10.4049/jimmunol.1000964

29. Gerstmayer B, Küsters D, Gebel S, Müller T, Van Miert E, Hofmann K, et al. Identification of Relm $\gamma$, A Novel Resistin-Like Molecule With a Distinct Expression Pattern. Genomics (2003) 81:588-95. doi: 10.1016/S0888-7543 (03)00070-3

30. Ghosh S, Singh AK, Aruna B, Mukhopadhyay S, Ehtesham NZ. The Genomic Organization of Mouse Resistin Reveals Major Differences From the Human Resistin: Functional Implications. Gene (2003) 305(1):27-34. doi: 10.1016/s0378-1119(02)01213-1

31. Steppan CM, Brown EJ, Wright CM, Bhat S, Banerjee RR, Dai CY, et al. A Family of Tissue-Specific Resistin-Like Molecules. Proc Natl Acad Sci USA (2001) 98(2):502-6. doi: 10.1073/pnas.98.2.502

32. Strausberg RL, Feingold EA, Grouse LH, Derge JG, Klausner RD, Collins FS, et al. Generation and Initial Analysis of More Than 15,000 Full-Length Human and Mouse cDNA Sequences. Proc Natl Acad Sci USA (2002) 99 (26):16899-903. doi: 10.1073/pnas.242603899

33. Patel SD, Rajala MW, Rossetti L, Scherer PE, Shapiro L. DisulfideDependent Multimeric Assembly of Resistin Family Hormones. Science (2004) 304(5674):1154-8. doi: 10.1126/science.1093466

34. Suragani M, Aadinarayana VD, Pinjari AB, Tanneeru K, Guruprasad L, Banerjee S, et al. Human Resistin, a Proinflammatory Cytokine, Shows Chaperone-Like Activity. Proc Natl Acad Sci USA (2013) 110(51):20467-72. doi: 10.1073/pnas.1306145110

35. Lee S, Lee H, Kwon Y, Lee SE, Cho Y, Kim J, et al. Adenylyl CyclaseAssociated Protein 1 Is a Receptor for Human Resistin and Mediates Inflammatory Actions of Human Monocytes. Cell Metab (2014) 19 (3):484-97. doi: 10.1016/j.cmet.2014.01.013

36. Tarkowski A, Bjersing J, Shestakov A, Bokarewa MI. Resistin Competes With Lipopolysaccharide for Binding to Toll-Like Receptor 4. J Cell Mol Med (2010) 14(6B):1419-31. doi: 10.1111/j.1582-4934.2009.00899.x

37. Mishra B, Reiling S, Zarena D, Wang G. Host Defense Antimicrobial Peptides as Antibiotics: Design and Application Strategies. Curr Opin Chem Biol (2017) 38:87-96. doi: 10.1016/j.cbpa.2017.03.014

38. Gerber M, Boettner A, Seidel B, Lammert A, Bar J, Schuster E, et al. Serum Resistin Levels of Obese and Lean Children and Adolescents: Biochemical Analysis and Clinical Relevance. J Clin Endocrinol Metab (2005) 90(8):45039. doi: 10.1210/jc.2005-0437

39. Aruna B, Islam A, Ghosh S, Singh AK, Vijayalakshmi M, Ahmad F, et al. Biophysical Analyses of Human Resistin: Oligomer Formation Suggests Novel Biological Function. Biochemistry (2008) 47(47):12457-66. doi: 10.1021/bi801266k

40. Silswal N, Singh AK, Aruna B, Mukhopadhyay S, Ghosh S, Ehtesham NZ. Human Resistin Stimulates the Pro-Inflammatory Cytokines TNF- $\alpha$ and IL-12 in Macrophages by NF-kb-Dependent Pathway. Biochem Biophys Res Commun (2005) 334(4):1092-101. doi: 10.1016/j.bbrc.2005. 06.202

41. Aruna B, Ghosh S, Singh AK, Mande SC, Srinivas V, Chauhan R, et al. Human Recombinant Resistin Protein Displays a Tendency to Aggregate by Forming Intermolecular Disulfide Linkages. Biochemistry (2003) 42 (36):10554-9. doi: 10.1021/bi034782v

42. Adeghate E. An Update on the Biology and Physiology of Resistin. Cell Mol Life Sci (2004) 61(19-20):2485-96. doi: 10.1007/s00018-004-4083-2

43. Schwartz DR, Lazar MA. Human Resistin: Found in Translation From Mouse to Man. Trends Endocrinol Metab (2011) 22(7):259-65. doi: 10.1016/ j.tem.2011.03.005

44. Harrison WJ, Bull JJ, Seltmann H, Zouboulis CC, Philpott MP. Expression of Lipogenic Factors Galectin-12, Resistin, SREBP-1, and SCD in Human Sebaceous Glands and Cultured Sebocytes. J Invest Dermatol (2007) 127 (6):1309-17. doi: 10.1038/sj.jid.5700743

45. Savage DB, Sewter CP, Klenk ES, Segal DG, Vidal-Puig A, Considine RV, et al. Resistin/Fizz3 Expression in Relation to Obesity and Peroxisome Proliferator-Activated Receptor-Gamma Action in Humans. Diabetes (2001) 50(10):2199-202. doi: 10.2337/diabetes.50.10.2199
46. Lu S, Shieh W, Chen C, Hsu S, Chen H. Lipopolysaccharide Increases Resistin Gene Expression In Vivo and In Vitro. FEBS Lett (2002) 530(13):158-62. doi: 10.1016/s0014-5793(02)03450-6

47. Kaser S, Kaser A, Sandhofer A, Ebenbichler CF, Tilg H, Patsch JR. Resistin Messenger-RNA Expression Is Increased by Proinflammatory Cytokines In Vitro. Biochem Biophys Res Commun (2003) 309(2):286-90. doi: 10.1016/ j.bbrc.2003.07.003

48. Lehrke M, Reilly MP, Millington SC, Iqbal N, Rader DJ, Lazar MA. An Inflammatory Cascade Leading to Hyperresistinemia in Humans. PloS Med (2004) 1(2):e45. doi: 10.1371/journal.pmed.0010045

49. Li B, Fang J, Zuo Z, Yin S, He T, Yang M, et al. Activation of Porcine Alveolar Macrophages by Actinobacillus Pleuropneumoniae Lipopolysaccharide Via the Toll-Like Receptor 4/NF-kb-Mediated Pathway. Infect Immun (2018) 86 (3):e00642-17. doi: 10.1128/IAI.00642-17

50. Babu S, Kumaraswami V, Nutman TB. Alternatively Activated and Immunoregulatory Monocytes in Human Filarial Infections. J Infect Dis (2009) 199(12):1827-37. doi: 10.1086/599090

51. Semnani RT, Mahapatra L, Moore V, Sanprasert V, Nutman TB. Functional and Phenotypic Characteristics of Alternative Activation Induced in Human Monocytes by Interleukin-4 or the Parasitic Nematode Brugia Malayi. Infect Immun (2011) 79(10):3957-65. doi: 10.1128/IAI.05191-11

52. Snäll J, Linnér A, Uhlmann J, Siemens N, Ibold H, Janos M, et al. Differential Neutrophil Responses to Bacterial Stimuli: Streptococcal Strains Are Potent Inducers of Heparin-Binding Protein and Resistin-Release. Sci Rep (2016) 6:21288. doi: $10.1038 /$ srep 21288

53. Uhlmann J, Siemens N, Kai-Larsen Y, Fiedler T, Bergman P, Johansson L, et al. Phosphoglycerate Kinase-a Novel Streptococcal Factor Involved in Neutrophil Activation and Degranulation. J Infect Dis (2016) 214(12):187683. doi: 10.1093/infdis/jiw450

54. Furugen R, Hayashida H, Saito T. Porphyromonas Gingivalis and Escherichia Coli Lipopolysaccharide Causes Resistin Release From Neutrophils. Oral Dis (2013) 19(5):479-83. doi: 10.1111/odi.12027

55. Hiroshima Y, Bando M, Inagaki Y, Mihara C, Kataoka M, Murata H, et al. Resistin in Gingival Crevicular Fluid and Induction of Resistin Release by Porphyromonas Gingivalis Lipopolysaccharide in Human Neutrophils. J Periodontal Res (2012) 47(5):554-62. doi: 10.1111/j.16000765.2011.01466.x

56. Johansson L, Linner A, Sunden-Cullberg J, Haggar A, Herwald H, Lore K, et al. Neutrophil-Derived Hyperresistinemia in Severe Acute Streptococcal Infections. J Immunol (2009) 183(6):4047-54. doi: 10.4049/jimmunol. 0901541

57. Furugen R, Hayashida H, Yoshii Y, Saito T. Neutrophil-Derived Resistin Release Induced by Aggregatibacter Actinomycetemcomitans. FEMS Microbiol Lett (2011) 321(2):175-82. doi: 10.1111/j.1574-6968.2011.02334.x

58. Goodman DS. Vitamin A. And Retinoids in Health and Disease. N Engl J Med (1984) 310(16):1023-31. doi: 10.1056/NEJM198404193101605

59. Bates CJ. Vitamin a. Lancet (1995) 345(8941):31-5. doi: 10.1016/s0140-6736 (95)91157-x

60. Elder JT, Fisher GJ, Zhang Q, Eisen D, Krust A, Kastner P, et al. Retinoic Acid Receptor Gene Expression in Human Skin. J Invest Dermatol (1991) 96 (4):425-33. doi: 10.1111/1523-1747.ep12469889

61. Idres N, Marill J, Flexor MA, Chabot GG. Activation of Retinoic Acid Receptor-Dependent Transcription by All-Trans-Retinoic Acid Metabolites and Isomers. J Biol Chem (2002) 277(35):31491-8. doi: 10.1074/ jbc.M205016200

62. Felipe F, Bonet ML, Ribot J, Palou A. Modulation of Resistin Expression by Retinoic Acid and Vitamin A Status. Diabetes (2004) 53(4):882-9. doi: $10.2337 /$ diabetes.53.4.882

63. Grice EA, Segre JA. The Skin Microbiome. Nat Rev Microbiol (2011) 9:24453. doi: 10.1038/nrmicro2537

64. Mukherjee S, Vaishnava S, Hooper LV. Multi-Layered Regulation of Intestinal Antimicrobial Defense. Cell Mol Life Sci (2008) 65(19):3019-27. doi: 10.1007/s00018-008-8182-3

65. Lai Y, Gallo RL. Amped Up Immunity: How Antimicrobial Peptides Have Multiple Roles in Immune Defense. Trends Immunol (2009) 30(3):131-41. doi: 10.1016/j.it.2008.12.003

66. Gallo RL, Hooper LV. Epithelial Antimicrobial Defence of the Skin and Intestine. Nat Rev Immunol (2012) 12(7):503-16. doi: 10.1038/nri3228 
67. Malik E, Dennison SR, Harris F, Phoenix DA. Ph Dependent Antimicrobial Peptides and Proteins, Their Mechanisms of Action and Potential as Therapeutic Agents. Pharmaceuticals (Basel) (2016) 9(4):67. doi: 10.3390/ ph9040067

68. Miller L, Singbartl K, Chroneos ZC, Ruiz-Velasco V, Lang CH, Bonavia A. Resistin Directly Inhibits Bacterial Killing in Neutrophils. Intensive Care Med Exp (2019) 7(1):30. doi: 10.1186/s40635-019-0257-y

69. Yu S, Zuo Z, Cui H, Li M, Peng X, Zhu L, et al. Transcriptional Profiling of Hilar Nodes From Pigs After Experimental Infection With Actinobacillus Pleuropneumoniae. Int J Mol Sci (2013) 14(12):23516-32. doi: 10.3390/ ijms 141223516

70. Zuo Z, Cui H, Li M, Peng X, Zhu L, Zhang M, et al. Transcriptional Profiling of Swine Lung Tissue After Experimental Infection With Actinobacillus Pleuropneumoniae. Int J Mol Sci (2013) 14(5):10626-60. doi: 10.3390/ ijms 140510626

71. Li B, Fang J, Zuo Z, Yin S, He T, Yang M, et al. Activation of the Porcine Alveolar Macrophages Via Toll-Like Receptor 4/NF-kb Mediated Pathway Provides a Mechanism of Resistin Leading to Inflammation. Cytokine (2018) 110:357-66. doi: 10.1016/j.cyto.2018.04.002

72. Westerhoff HV, Juretić D, Hendler RW, Zasloff M. Magainins and the Disruption of Membrane-Linked Free-Energy Transduction. Proc Natl Acad Sci USA (1989) 86(17):6597-601. doi: 10.1073/pnas.86.17.6597

73. Mukherjee S, Zheng H, Derebe MG, Callenberg KM, Partch CL, Rollins D, et al. Antibacterial Membrane Attack by a Pore-Forming Intestinal C-Type Lectin. Nature (2014) 505(7481):103-7. doi: 10.1038/nature12729

74. Bierbaum G, Sahl HG. Induction of Autolysis of Staphylococci by the Basic Peptide Antibiotics Pep 5 and Nisin and Their Influence on the Activity of Autolytic Enzymes. Arch Microbiol (1985) 141(3):249-54. doi: 10.1007/ BF00408067

75. Matsuzaki K. Why and How Are Peptide-Lipid Interactions Utilized for Self-Defense? Magainins and Tachyplesins as Archetypes. Biochim Biophys Acta (1999) 1462(1-2):1-10. doi: 10.1016/S0005-2736(99)00197-2

76. Jenssen H, Hamill P, Hancock REW. Peptide Antimicrobial Agents. Clin Microbiol Rev (2006) 19(3):491-511. doi: 10.1128/CMR.00056-05

77. Levy O. Antimicrobial Proteins and Peptides: Anti-Infective Molecules of Mammalian Leukocytes. J Leukoc Biol (2004) 76(5):909-25. doi: 10.1189/ jlb.0604320

78. Greer A, Zenobia C, Darveau RP. Defensins and LL-37: A Review of Function in the Gingival Epithelium. Periodontol 2000 (2013) 63(1):67-79. doi: 10.1111/prd.12028

79. Bowdish DM, Davidson DJ, Hancock RE. Immunomodulatory Properties of Defensins and Cathelicidins. Curr Top Microbiol Immunol (2006) 306:2766. doi: 10.1007/3-540-29916-5_2

80. Shai Y. Mechanism of the Binding, Insertion and Destabilization of Phospholipid Bilayer Membranes by U-Helical Antimicrobial and Cell Non-Selective Membrane-Lytic Peptides. Biochim Biophys Acta (1999) 1462(1-2):55-70. doi: 10.1016/s0005-2736(99)00200-x

81. Walcher D, Hess K, Berger R, Aleksic M, Heinz P, Bach H, et al. Resistin: A Newly Identified Chemokine for Human CD4-Positive Lymphocytes. Cardiovasc Res (2010) 85(1):167-74. doi: 10.1093/cvr/cvp278

82. Sánchez-Solana B, Laborda J, Baladrón V. Mouse Resistin Modulates Adipogenesis and Glucose Uptake in 3T3-L1 Preadipocytes Through the ROR1 Receptor. Mol Endocrinol (2012) 26:110-27. doi: 10.1210/me. 2011-1027

83. Daquinag AC, Zhang Y, Amaya-Manzanares F, Simmons PJ, Kolonin MG. An Isoform of Decorin Is a Resistin Receptor on the Surface of Adipose Progenitor Cells. Cell Stem Cell (2011) 9:74-86. doi: 10.1016/j.stem.2011.05.017

84. Miao J, Benomar Y, Al Rifai S, Poizat G, Riffault L, Crépin D, et al. Resistin Inhibits Neuronal Autophagy Through Toll-Like Receptor 4. J Endocrinol (2018) 238:77-89. doi: 10.1530/JOE-18-0096

85. Li Z, Wang X, Pan H, Yang H, Li X, Zhang K, et al. Resistin Promotes CCL4 Expression Through Toll-Like Receptor-4 and Activation of the P38-MAPK and NF-Kappab Signaling Pathways: Implications for Intervertebral Disc Degeneration. Osteoarthritis Cartilage (2017) 25:341-50. doi: 10.1016/ j.joca.2016.10.002

86. Farnaud S, Evans RW. Lactoferrin-A Multifunctional Protein With Antimicrobial Properties. Mol Immunol (2003) 40(7):395-405. doi: 10.1016/ s0161-5890(03)00152-4
87. Levy O, Elsbach P. Bactericidal/Permeability-Increasing Protein in Host Defense and Its Efficacy in the Treatment of Bacterial Sepsis. Curr Infect Dis Rep (2007) 3(5):407-12. doi: 10.1007/s11908-007-1007-y

88. Burton MF, Steel PG. The Chemistry and Biology of LL-37. Nat Prod Rep (2009) 26(12):1572-84. doi: 10.1039/b912533g

89. Canny G, Levy O. Bactericidal/Permeability-Increasing Protein (BPI) and BPI Homologs at Mucosal Sites. Trends Immunol (2008) 29(11):541-7. doi: 10.1016/j.it.2008.07.012

90. Matviw H, Yu G, Young D. Identification of a Human Cdna Encoding a Protein That Is Structurally and Functionally Related to the Yeast Adenylyl Cyclase-Associated CAP Proteins. Mol Cell Biol (1992) 12:5033-40. doi: 10.1128/MCB.12.11.5033

91. WakeelL A, Kuriakose JA, Mcbride JW. An Ehrlichia Chaffeensis Tandem Repeat Protein Interacts With Multiple Host Targets Involved in Cell Signaling, Transcriptional Regulation, and Vesicle Trafficking. Infect Immun (2009) 77:1734-45. doi: 10.1128/IAI.00027-09

92. Kinsner A, Boveri M, Hareng L, Brown GC, Coecke S, Hartung T, et al. Highly Purified Lipoteichoic Acid Induced Pro-Inflammatory Signalling in Primary Culture of Rat Microglia Through Toll-Like Receptor 2: Selective Potentiation of Nitric Oxide Production by Muramyl Dipeptide. J Neurochem (2006) 99(2):596-607. doi: 10.1111/j.1471-4159.2006.04085.x

93. Son YM, Ahn SM, Jang MS, Moon YS, Kim SH, Cho K, et al. Immunomodulatory Effect of Resistin in Human Dendritic Cells Stimulated With Lipoteichoic Acid From Staphylococcus Aureus. Biochem Biophys Res Commun (2008) 376(3):599-604. doi: 10.1016/j.bbrc.2008.09.037

94. Amulic B, Cazalet C, Hayes GL, Metzler KD, Zychlinsky A. Neutrophil Function: From Mechanisms to Disease. Annu Rev Immunol (2012) 30:45989. doi: 10.1146/annurev-immunol-020711-074942

95. Sørensen OE, Borregaard N. Neutrophil Extracellular Traps - The Dark Side of Neutrophils. J Clin Invest (2016) 126:1612-20. doi: 10.1172/JCI84538

96. Bonavia A, Miller L, Kellum JA, Singbartl K. Hemoadsorption Corrects Hyperresistinemia and Restores Anti-Bacterial Neutrophil Function. Intensive Care Med Exp (2017) 5(1):36. doi: 10.1186/s40635-017-0150-5

97. Kienle K, Lämmermann T. Neutrophil Swarming: An Essential Process of the Neutrophil Tissue Response. Immunol Rev (2016) 273(1):76-93. doi: $10.1111 / \mathrm{imr} .12458$

98. de Oliveira S, Rosowski EE, Huttenlocher A. Neutrophil Migration in Infection and Wound Repair: Going Forward in Reverse. Nat Rev Immunol (2016) 16(6):378-91. doi: 10.1038/nri.2016.49

99. Esche C, Stellato C, Beck LA. Chemokines: Key Players in Innate and Adaptive Immunity. J Invest Dermatol (2005) 125(4):615-28. doi: 10.1111/ j.0022-202X.2005.23841.x

100. Zhang Z, Xing X, Hensley G, Chang L, Liao W, Abu-Amer Y, et al. Resistin Induces Expression of Pro-Inflammatory Cytokines and Chemokines in Human Articular Chondrocytes Via Transcription and Mrna Stabilization. Arthritis Rheum (2010) 62(7):1993-2003. doi: 10.1002/art.27473

101. Sundén-Cullberg J, Nyström T, Lee ML, Mullins GE, Tokics L, Andersson J, et al. Pronounced Elevation of Resistin Correlates With Severity of Disease in Severe Sepsis and Septic Shock. Crit Care Med (2007) 35(6):1536-42. doi: 10.1097/01.CCM.0000266536.14736.03

102. Macdonald SPJ, Bosio E, Neil C, Arendts G, Burrows S, Smart L, et al. Resistin and NGAL Are Associated With Inflammatory Response, Endothelial Activation and Clinical Outcomes in Sepsis. Inflammation Res (2017) 66(7):611-19. doi: 10.1007/s00011-017-1043-5

103. Chen W, Lin C, Kuo S, Liu S, Lu Y, Chen Y, et al. Resistin Enhances VCAM-1 Expression and Monocyte Adhesion in Human Osteoarthritis Synovial Fibroblasts by Inhibiting Mir-381 Expression Through the PKC, P38, and JNK Signaling Pathways. Cells (2020) 9(6):1369. doi: 10.3390/cells9061369

104. Manduteanu I, Dragomir E, Calin M, Pirvulescu M, Gan AM, Stan D, et al. Resistin Up-Regulates Fractalkine Expression in Human Endothelial Cells: Lack of Additive Effect With TNF- $\alpha$. Biochem Biophys Res Commun (2009) 381(1):96-101. doi: 10.1016/j.bbrc.2009.02.015

105. Verma S, Li S, Wang C, Fedak PWM, Li R, Weisel RD, et al. Resistin Promotes Endothelial Cell Activation: Further Evidence of AdipokineEndothelial Interaction. Circulation (2003) 108(6):736-40. doi: 10.1161/ 01.CIR.0000084503.91330.49

106. Hsu WY, Chao YW, Tsai YL, Lien CC, Chang CF, Deng MC, et al. Resistin Induces Monocyte-Endothelial Cell Adhesion by Increasing ICAM-1 and 
VCAM-1 Expression in Endothelial Cells Via P38mapk-Dependent Pathway. J CELL PHYSIOL226: 2181-2188. J Cell Physiol (2011) 226 (8):2181-8. doi: 10.1002/jcp.22555

107. Pirvulescu MM, Gan AM, Stan D, Simion V, Calin M, Butoi E, et al. Subendothelial Resistin Enhances Monocyte Transmigration in a Co-Culture of Human Endothelial and Smooth Muscle Cells by Mechanisms Involving Fractalkine, MCP-1 and Activation of TLR4 and Gi/O Proteins Signaling. Int J Biochem Cell Biol (2014) 50:29-37. doi: 10.1016/j.biocel.2014.01.022

108. Gao F, Si F, Feng S, Yi Q, Liu R. Resistin Enhances Inflammatory Cytokine Production in Coronary Artery Tissues by Activating the NF- $k b$ Signaling. BioMed Res Int (2016) 2016:1-8. doi: 10.1155/2016/3296437

109. Pirvulescu M, Manduteanu I, Gan AM, Stan D, Simion V, Butoi E, et al. A Novel Pro-Inflammatory Mechanism of Action of Resistin in Human Endothelial Cells: Up-Regulation of SOCS3 Expression Through STAT3 Activation. Biochem Biophys Res Commun (2012) 422(2):321-6. doi: $10.1016 / j . b b r c .2012 .04 .159$

110. Cho Y, Lee S, Lee H, Hur J, Lee S, Youn S, et al. Adipokine Resistin is a Key Player to Modulate Monocytes, Endothelial Cells, and Smooth Muscle Cells, Leading to Progression of Atherosclerosis in Rabbit Carotid Artery. J Am Coll Cardiol (2011) 57(1):99-109. doi: 10.1016/j.jacc.2010.07.035

111. Chen K, Liu J, Cao X. Regulation of Type I Interferon Signaling in Immunity and Inflammation: A Comprehensive Review. J Autoimmun (2017) 83:1-11. doi: 10.1016/j.jaut.2017.03.008

112. Cohen G, Ilic D, Raupachova J, Hörl WH. Resistin Inhibits Essential Functions of Polymorphonuclear Leukocytes. J Immunol (2008) 181 (6):3761-8. doi: 10.4049/jimmunol.181.6.3761

113. Chao W, Yen C, Wu Y, Chen S, Hsieh C, Chang T, et al. Increased Resistin may Suppress Reactive Oxygen Species Production and Inflammasome
Activation in Type 2 Diabetic Patients With Pulmonary Tuberculosis Infection. Microbes Infect (2015) 17(3):195-204. doi: 10.1016/j.micinf.2014. 11.009

114. Singbartl K, Miller L, Ruiz-Velasco V, Kellum JA. Reversal of Acute Kidney Injury-Induced Neutrophil Dysfunction. Crit Care Med (2016) 44(7):492501. doi: 10.1097/CCM.0000000000001472

115. Nieto JC, Perea L, Soriano G, Zamora C, Cantó E, Medina A, et al. Ascitic Fluid Regulates the Local Innate Immune Response of Patients With Cirrhosis. J Leukoc Biol (2018) 104(4):833-41. doi: 10.1002/JLB.3A0218072R

116. Son YM, Ahn SM, Kim GR, Moon YS, Kim SH, Park Y, et al. Resistin Enhances the Expansion of Regulatory T Cells Through Modulation of Dendritic Cells. BMC Immunol (2010) 11:33. doi: 10.1186/1471-2172-11-33

117. Wan YY, Flavell RA. TGF-Beta and Regulatory T Cell in Immunity and Autoimmunity. J Clin Immunol (2008) 28(6):647-59. doi: 10.1007/s10875008-9251-y

Conflict of Interest: The authors declare that the research was conducted in the absence of any commercial or financial relationships that could be construed as a potential conflict of interest.

Copyright () 2021 Li, Yang, Cai, Guo, Fang, Cui, Gou, Deng, Wang and Zuo. This is an open-access article distributed under the terms of the Creative Commons Attribution License (CC BY). The use, distribution or reproduction in other forums is permitted, provided the original author(s) and the copyright owner(s) are credited and that the original publication in this journal is cited, in accordance with accepted academic practice. No use, distribution or reproduction is permitted which does not comply with these terms. 